\title{
Rancang Bangun Pengaman Motor Honda Beat Menggunakan Sistem Arduino Uno
}

\author{
Heri Sunaryatin ${ }^{1 * *}$, Willy Artika Rikarda ${ }^{2}$ Imam Mualim³ \\ Program Studi Ilmu Komputer, Universitas Nahdlatul Ulama Lampung, Indonesia. \\ 1'heris021@gmail.com, ${ }^{2}$ willyar.mti@gmail.com, ${ }^{3}$ imammualim200281@gmail.com \\ *corresponding author
}

INFO ARTIKEL

Sejarah Artikel

Diterima: 5 Juli 2021

Direvisi: 25 Agustus 2021

Diterbitkan: 31 Agustus 2021

Kata Kunci

RFID

Pengaman Motor

Arduino Uno

\begin{abstract}
ABSTRAK
Kemajuan teknologi saat ini sangatlah pesat. Masyarakat luas menggunakan kendaraan sepeda motor untuk memudahkan akses ke berbagai tempat. Namun, maraknya pencurian dan pembegalan yang terjadi pada sepeda motor khususnya Sepeda Motor Merk Honda Beat membuat banyak orang berusaha untuk lebih meningkatkan sistem keamanan sepeda motor tersebut, baik menggunakan alat-alat pengaman, Untuk mengurangi hal-hal yang tidak kita inginkan kunci kontak sepeda motor diganti dengan kartu.yang di atur dan mempunyai kode khusus,yaitu Radio Frequency Identification (RFID). Metode yang digunakan pada penelitian ini adalah metode Riset and Development yang bertujuan menghasilkan produk tertentudan menguji keefektifan produk tersebut. Metode ini diterapkan pada prosedur penelitian dalam 7 tahapan yaitu : (1) mulai, (2) analisa kebutuhan, (3) perencanaan dan perancangan, (4) analisa kebutuhan sistem, (5) pengujian alat, (6) analisa data (7) membuat laporan. Kunci Radio Frequency Identification (RFID) juga menggunakan kartu tag ID sebagai kartu identitas atau pengenal ketika hendak menghidupkan atau mematikan mesin sepeda motor Honda Beat. Kinerja kartu ini juga didukung oleh microcontroller Arduino Uno dan relay. Dalam perancangan alat ini, kami menghubungkan kabel-kabel terdiri dari hardware Arduino Uno, RFID reader, Relay dan saklar O/I dengan sistem kelistrikan sepeda motor Honda Beat. Untuk penggunaan alat ini, dilakukan dengan tiga tahap (scan) untuk menghidupkan dan mematikan mesin sepeda motor. Scan pertama, untuk memposisi ON kan kelistrikan sepeda motor. Scan kedua, untuk menghidupkan mesin sepeda motor. Scan ketiga, untuk mematikan mesin sepeda motor.
\end{abstract}

\section{PENDAHULUAN}

Saat ini kemajuan dibidang teknologi sangat pesat. Masyarakat luas tidak terlepas dari kendaraan sepeda motor untuk memudahkan transportasi. Namun, maraknya pencurian membuat banyak orang berupaya lebih meningkatkan tentang sistem keamanan sepeda motor tersebut. Untuk mengurangi hal yang tidak kita inginkan, maka dari itu penulis mencoba mengubah kunci kontak motor ini dengan sebuah kartu [1]. Oleh karena itu kendaraan ini tidak lagi mewujudkannya, penulis akan membuat sebuah rancangbangun sistem kunci kontak sepeda motor menggunakan Radio Frequency Identification (RFID) yang dijadikan system pengamanan dalam kendaraan sepeda motor. Penulis juga mengembangkan sensor RFID sebagai start / stop otomatis guna menghidupkan dan mematikan mesin sepeda motor Honda Beat [2].

Radio Frequency Identification (RFID) adalah suatu sistem yang mentransmisikan identitas tertentu berupa kode atau nomor unik dari suatu objek yang menggunakan gelombang frekuensi radio [3]. Teknologi termasuk bagian dari berbagai teknologi 
biometric seperti retinal scan. Batasan masalah dalam penelitian ini adalah pemakaian RFID reader sebagai sarana penerima adalah Modul RFID RC522dan RFID tag (transponder) sebagai kunci kontak secara otomatis pada suatu kendaraan bermotor Honda Beat untuk ON /OFFdan Starter. Selain itu, penggunaan modul RFID Mikrokontroler Arduino Uno digunakan untuk mengaktifkan Relay kunci kontak kendaraan sepeda motor Honda Beat [4].

Penelitian ini diharapkan mampu mengurangi tingkat kriminalitas dalam bentuk pencurian kendaraan bermotor, terutama sepeda motor Honda BEAT yang paling banyak terjadi kasus pencuriannya sehingga dapat menurunkan kasus tersebut seminimal mungkin. Sekaligus mampu mempermudah menyalakan kunci kontak, start dan mesin sepeda motor Honda Beat secara otomatis tanpa menggunakan kunci kontak manual. Selain itu, menambah referensi untuk sistem pengaman sepeda motor bagi masyarakat, sehingga dapat juga diaplikasikan ke semua sepeda motor selain sepeda motor Honda Beat.

\section{METODE}

Metode yang digunakan pada penelitian Sistem Pengaman Sepeda Motor Honda Beat berbasis RFID Arduino Uno adalah Metode Research and Development (Riset dan Pengembangan) [5]. Metode ini menerapkan prosedur dalam 7 tahapan yaitu :(1) Mulai, (2)Analisa kebutuhan, (3) Perencanaan dan Perancangan,(4) Analisa Kebutuhan sistem,(5) Pengujian alat,(6) Analisa Data,(7) Membuat laporan. Diagram metode penelitian ditunjukkan pada Gambar 1.

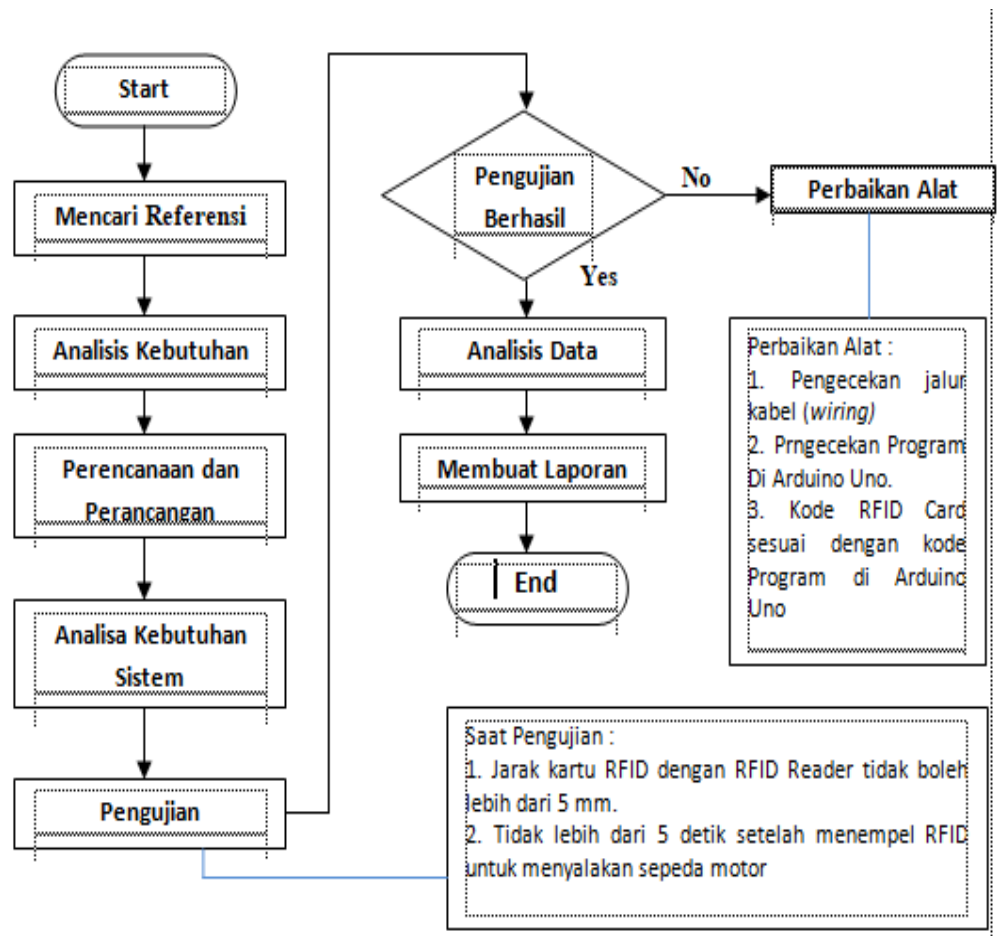

Gambar 1. Diagram metode penelitian

Referensi yang berkaitan dengan penelitian ini antara lain : Perancangan Kunci Kontak Sepeda Motor Menggunakan RFID Berbasis Arduino Uno dan penelitian lain dengan judul Sistem Keamanan Helm Berbasis RFID (Radio Frequency Identification) serta judul lainnya yakni Rancang Bangun Sistem Pengaman Sepeda Motor Menggunakan Radio Frequency Identification (RFID) dan Notifikasi Melalui Handphone, oleh karena itu penelitian ini bertujuan untuk merancang dan membangun 
Sistem Keamanan Sepeda Motor menggunakan sensor RFID efektif khususnya pada Sepeda Motor Honda Beat FI. Tahapan berikutnya setelah studi literatur yakni analisa kebutuhan alat dan bahan yang digunakan untuk membuat pintu otomatis. Kemudian, perancangan dimulai dengan pemograman melalui aplikasi Arduino lalu merancang komponen alat sampai bisa digunakan. Terakhir, melakukan uji coba secara berulang untuk menguji efisiensi dan keamanan dari alat Sistem Pengaman Sepeda Motor Honda Beat. Setelah uji coba berhasil tahap selanjutnya adalah membuat laporan penelitian.

\section{Alat dan Bahan}

Alat dan bahan yang digunakan untuk membuat Sistem pengaman kunci kontak Sepeda Motor Honda Beat menggunakan RFID dapat dilihat sebagai berikut:

1. RFID card sebagai output gelombang frekuensi berupa radio.

2. Blok RFID sebagai penerima gelombang radio.

3. Arduino Uno Set sebagai pengendali system secara keseluruhan dan telah diprogram.

4. LCD menampilkan tampilan yaitu Masukan Password, Password benar, Password salah.

5. Relay untuk mengatur arus yang masuk

6. Kabel dan skun sebagai penyambung rangkaian listrik di dalam program RFID arduino Uno dan juga untuk menghubungkan dengan Sepeda Motor Honda Beat di sistem kelistrikannya.

7. Fiber sebagai tempat rangkaian Arduino

8. Isolasi untuk menjaga kabel agar tidak konsleting atau hubungan pendek arus listrik.

9. Lem untuk meletakkan rangkaian pada kendaraan motor

10. Sepeda Motor Honda Beat FI sebagai bahan untuk penelitian.

11. Laptop untuk menginstal program ke Arduino Uno

12. Alat-lat pendukung lainnya seperti: Obeng,Tang, AVO meter, BorListrik, Gergaji, Solder, mistar, pena, serta Kunci Kombinasi.

\section{Waktu Penelitian}

Penelitian ini dilaksankan sejak Bulan Februari 2020 sampai dengan bulan Mei 2020 di Laboratorium Teknik Elektro, Universitas Nahdlatul Ulama Lampung, Purbolinggo, Lampung Timur, Lampung.

\section{Perancangan Sistem}

Pada bagian ini dijelaskan tahapan-tahapan kerangka penelitian yang digunakan dalam membuat sistem keamanan kendaraan bermotor Honda Beat yang menggunakan Arduino Uno yang berbasis RFID (Radio Frequency Identification).

Diagram blok merupakan rangkaian bagian penting didalam perancangan alat elektronik, karena diagram blok dapat diketahui bahwa prinsip kinerja secara keseluruan dari rangkaian elektronik ini yang dibuat. Sehingga total blok dari alat yang dibuat dapat terbentuk suatu system yang dapat dimanfaatkan sistem yang bekerja sesuai dengan perancanganya. total dari diagram blok dari suatu alat yang dibuat dapat dilihat pada Gambar 2 


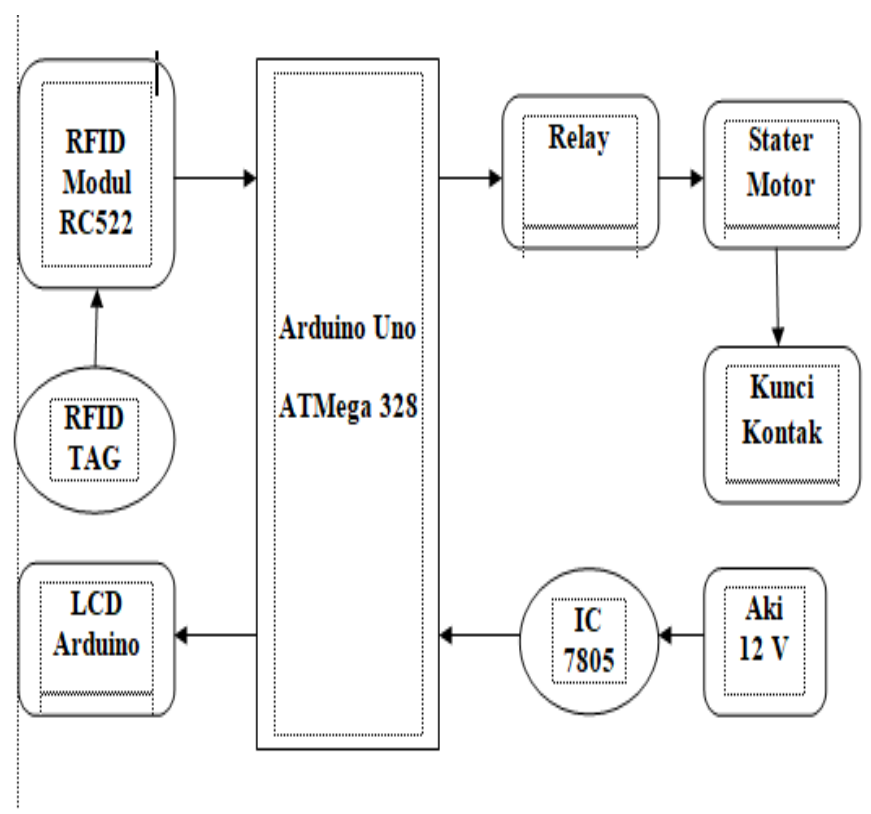

Gambar 2. Diagram Blok

Alur kerja diagram blok sistem dalam Gambar 2 dapat diuraikan sebagai berikut:

1. RFID akan menerima hasil verifikasi dari $T A G$ yang disandingkan apabila verifikasi ID sesuai dengan yang telah didaftarkan Arduino, selanjutnya data akan diproses.

2. Apabila data ID sesuai dengan apa yang didaftarkan maka Arduino akan memproses perintah mentranfer sinyal ke relay yang awal kondisi open menjadi tutup untuk dapat mengalir listrik.

3. Setelah itu kondisi relay close akan memutarkan stat kendaraan bermotor untuk dapat menyalakan bermotormotor dan pada LCD tampil siap untuk ddapat stat motor

4. Disaat saat kondisi kunci motor " $O N$ " dan ID pada TAG Reader tidak cocok dengan program pada arduino, kondisi relay akan tetap open "OFF" yang akan mucul di Modul LCD "kartu tidak sesuai”.

Dalam semua perancangan baik hardware software, maka proses kerja dari alat tersebut yang dibuat dapat ditunjukkan dibawah ini:

1. Tampilan pertama kali di Display $L C D$ berarti kita menyiapkan RFID Tag untuk menjalankan program inni

2. Jika kartu RFID TAG yang sesuai dengan ID di Program. Jika Benar program akan berjalan dan Relay akan "ON" atau aktif. Jika IDnya berbeda, maka tampilan akses program akan ditolak karena kondisi relay "OFF" atau tidak aktif.

3. Setelah Relay aktif “ $O N$ ” untuk mengaktifkan system kelistrikan motor, maka motor dapat dinyalakan.

4. Terakhir tampilan menjadi normal untuk menempelkan kartu

Lebih jelasnya bisa dilihat flowchart dari sistem tersebut di Gambar 3. 


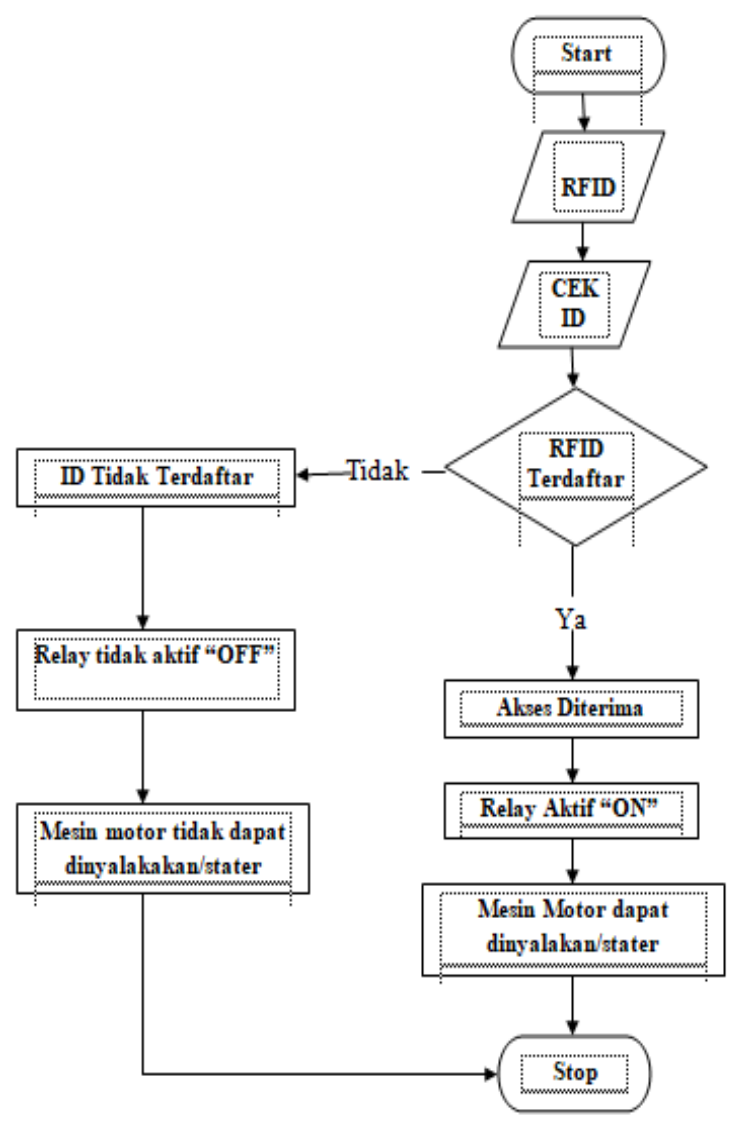

Gambar 3. Sistem Kerja Alat Penelitian

\section{HASIL DAN PEMBAHASAN}

Sistem Setelah RFID system dilaksanakan, perlu dilakukan berbagai proses pengujian untuk mengetahui kinerja perangkat serta menganalisa tingkat reliabilitas, kekurangan spesifikasi manfaat dari alat yang telah dibuat. Selain itu juga, pengujian tersebut juga dilakukan untuk mengetahui bagaimana keadaan system agar alat ini dapat beroperasi dengan optimal. Tahapan-tahapan yang dilakukan guna membuat System Pengaman kendaraan bermotor Honda Beat menggunakan RFID sebagai berikut:

\section{Pemrograman Arduino}

Pemrograman melalui Arduino pengujian ini dilakukan dengan menggunakan aplikasi arduino, aplikasi Arduino digunakan adalah versi 8.1.Pengujian Arduino ini dilakukan untuk mengetahui cara kerja dan fungsi dari masing masing komponen utama serta mengetahui cara pengoprasian dari alat ini.

\section{Pemrograman RFID dengan LCD}

Uji coba rangkaian RFID adalah dengan cara menempelkan card di RFID,maka secara otomatis data pada card akan terbaca secara otomatis dan mentranfer ke Arduino. Adapun program untuk membaca data yang ada di RFID. Bagian ini hanya terdiri dari sebuah Lcd 16x2 karakter yang berfungsi sebagai tampilan dari Card RFID Correct atau Incorrect. Lcd akan dihubungkan langsung ke Arduino sebagaimana pada Gambar 4. 


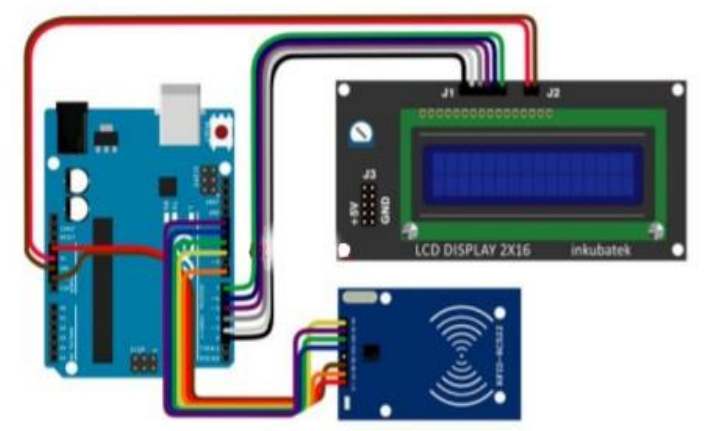

Gambar 4. Rancangan RFID dengan LCD

\section{Jalannya Program RFID}

Setelah program tersebut di Upload ke arduino maka tampilan pertama pada LCD adalah sebagaimana pada Gambar 5:

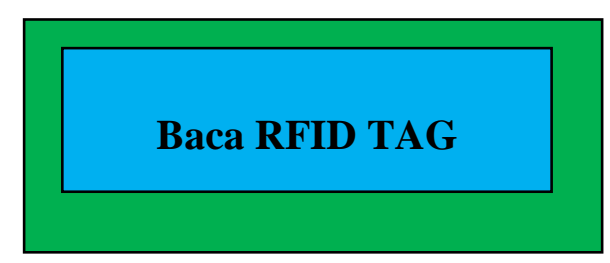

Gambar 5. Pembacaan RFID Tag di Display LCD

Selanjutnya dekatkan atau tempelkan RFID Tag ke RFID Reader (MFRC 522), maka pada LCD akan tampil data ID-nya. Contoh ID yang dipakai adalah "c7933133 " pada Gambar 6.

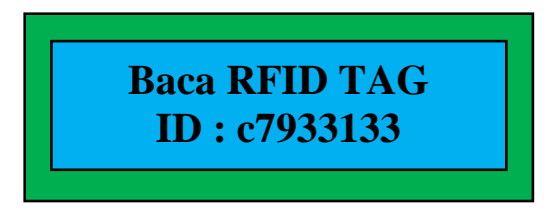

Gambar 6. Kode RFID tag di Display LCD

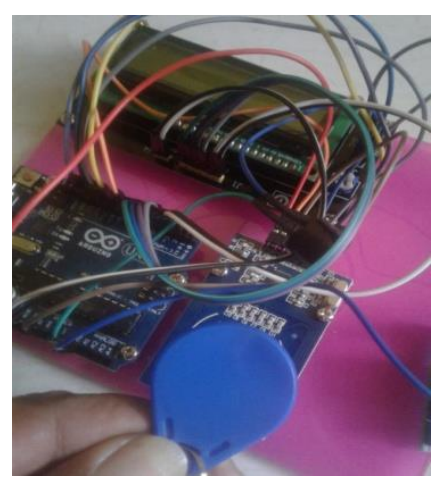

Gambar 7. Cara Pemakaian RFID Tag ke RFID Reader

Untuk lebih jelasnya dapat melihat flowchart untuk pemrograman RFID pada Gambar 8: 


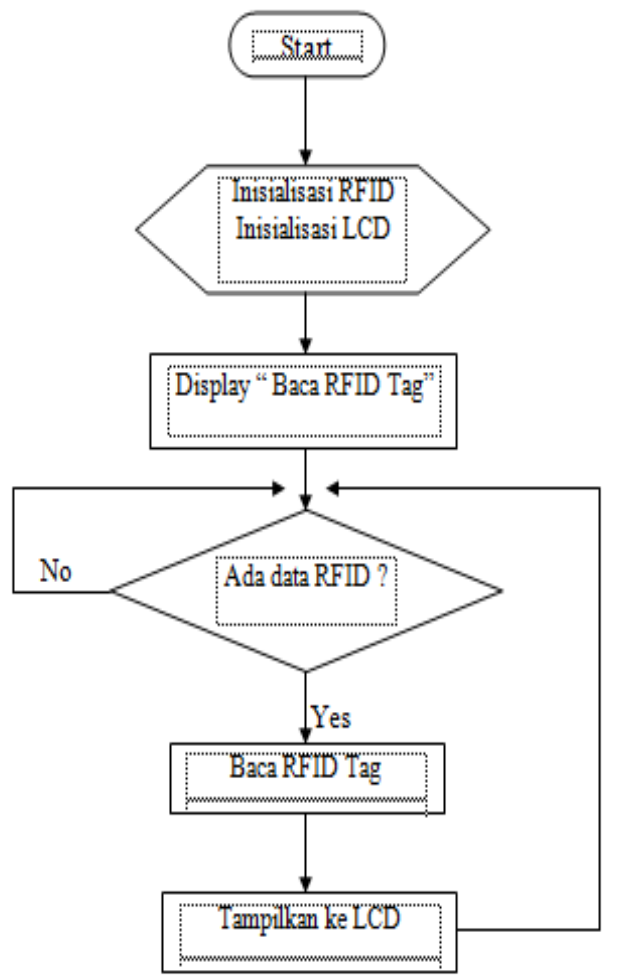

Gambar 8. Flowchart Pembacaan Kartu RFID

\section{Perancangan Arduino Uno Modul RC 522 pada Honda Beat}

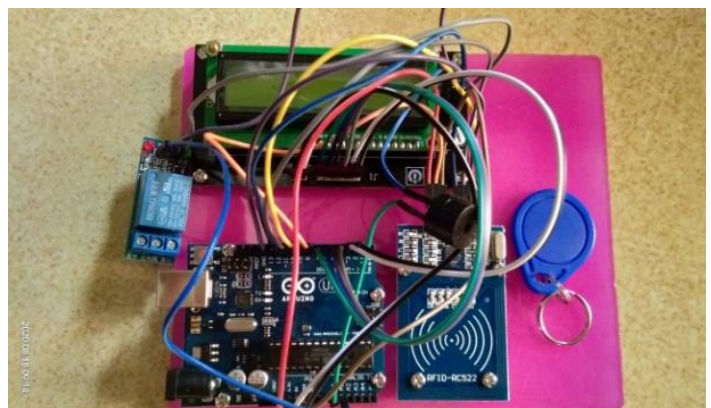

Gambar 9. Hasil Rancangan RFID Pengaman Sepeda Motor Beat

Jalannya Program Perancangan

1. Tampilan Pertama kali pada Alat di Layar LCD ditunjukkan pada Gambar 10.

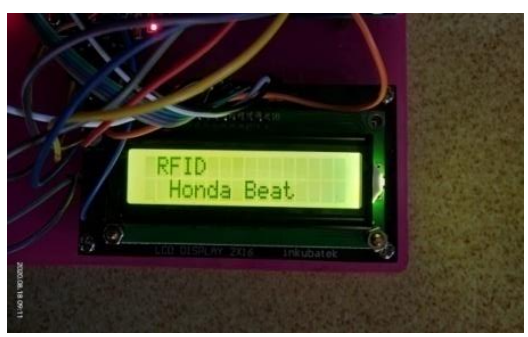

Gambar 10. Tampilan awal di LCD

2. Setelah 2 detik pada display atau layar LCD akan muncul perintah untuk menempelkan kartu RFID sebagaimana pada Gambar 11. 


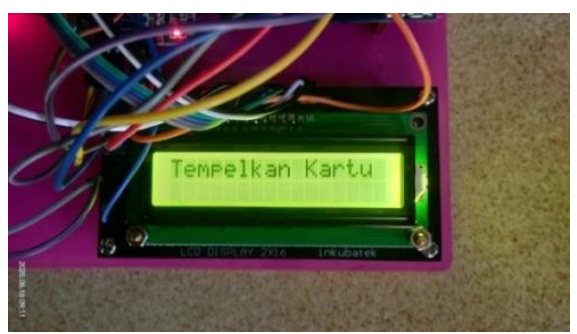

Gambar 11. Tampilan Kedua di Display LCD

3. Setelah Kartu RFID ditempelkan pada Modul MFRC 522 apakh sesuai dengan "ID Program".

4. Jika Benar maka Relay akan ON, maka sepeda motor siap distater atau dihidupkan, sebagaimana pada Gambar 12.

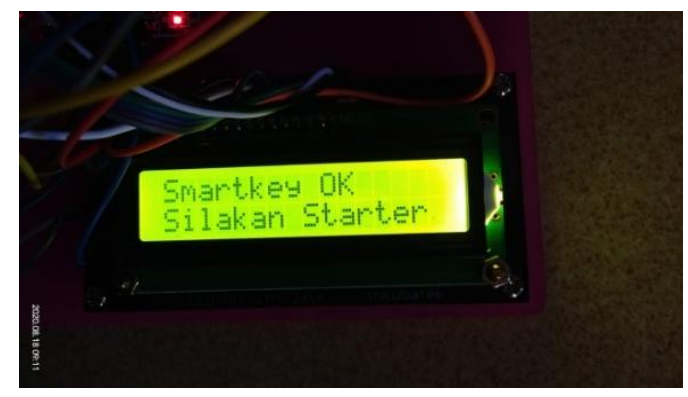

Gambar 12. Jika Kartu (RFID Tag) Benar tampilan di Display LCD

5. Jika RFID Tag tidak sesuai dengan ID Program maka di display atau layar LCD muncul tulisan “Kartu Salah” dan Relay tetap OFF. Ditunjukkan pada Gambar 13.

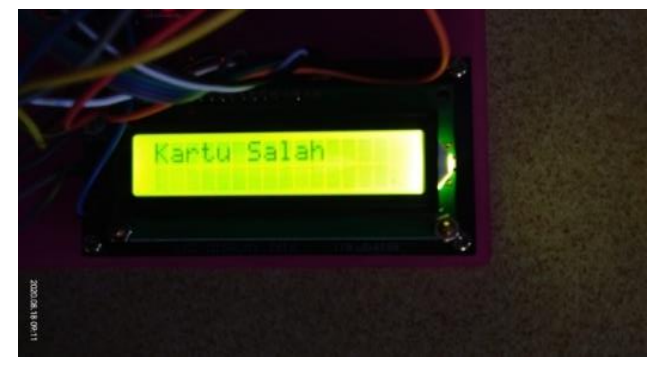

Gambar 13. Jika Kartu (RFID Tag) Salah tampilan di Display LCD

6. Karena Kartu RFID tidak sesuai maka program akan kembali ke awal sampai dengan penggunaan Kartu RFID yang benar sehingga motor dapat dihidupkan atau distarter.

Untuk lebih jelasnya jalannya program pada perancangan ini, dapat melihat flowchart pada Gambar 14. 


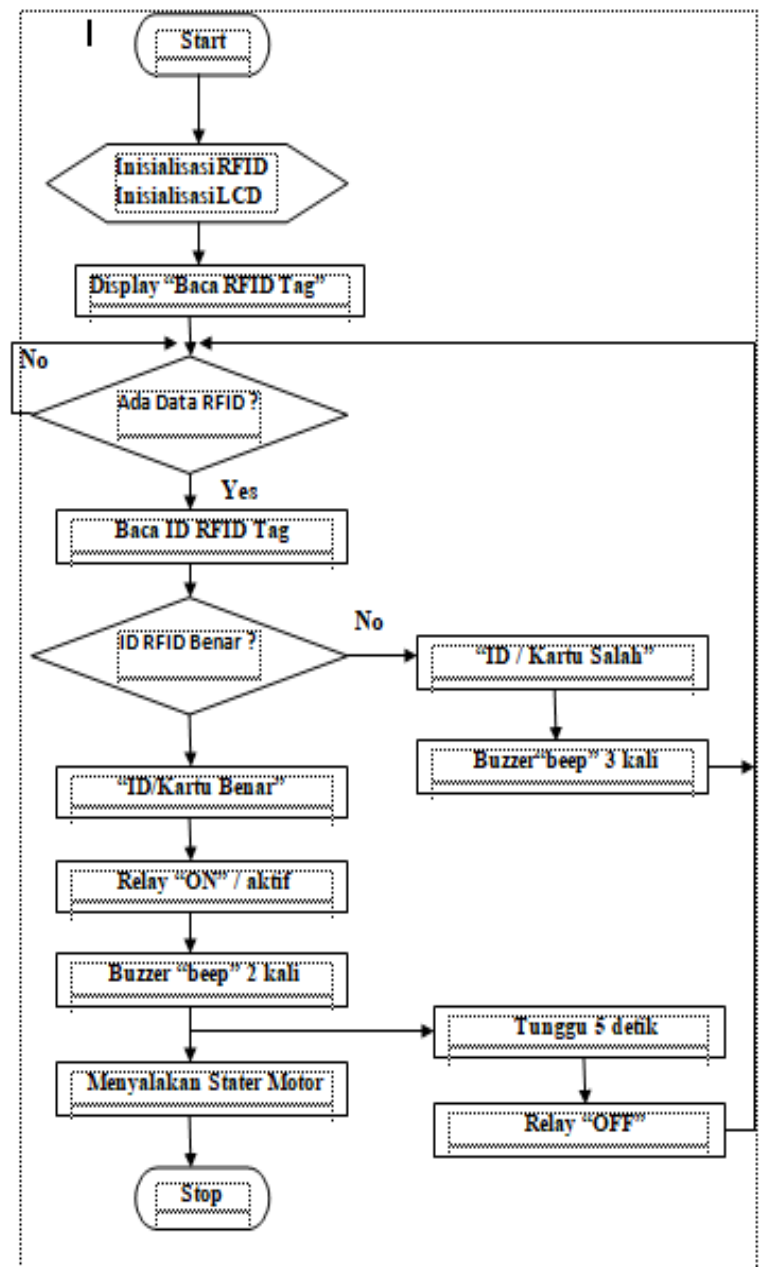

Gambar 14. Flowchart Sistem Pengaman Sepeda Motor Honda Beat Arduino Uno Modul RC 522

\section{Pengujian Sistem}

Setelah RFID sistem digunakan, perlu dilakukan berbagai ujicobaa untuk mengetahui bagaiman cara kerja suatu perangkat dan menganalisa tingkat keberhasilan, kekurangan spesifikasi manfaat dari alat yang telah dibuat. Selain itu,juga ujicoba ini juga dilakukan untuk mengetahui bagaimana sistem dapat terkondisikan agar alat ini dapat bekerja dengan sempurna. Dalam pengujian alat ini,semua komponen telah dipasang dan diprogram hingga menjadi sebuah miniature Sistem Pengaman Sepeda Motor Honda Beat. Pengujian dilakukan dengan menempelkan kartu RFID.

Pengujian ini akan diuji beberapa komponen yang terdiri dari :

\section{Pengujian Jarak antara RFID Tag dengan RFID Reader.}

Ujicoba dilakukan dengan menyandingkan RFID Tag Card ke RFID. Reader dengan jarak tertentu kemudian diukur oleh mistar pengukur. jika RFID Tag Card terdeteksi oleh RFID, Relay akan Aktif (ON) dan Buzzer berbunyi 2 kali dan di LCD juga muncul tulisan "Smartkey OK , Silahkan Stater" sehingga motor siap distater. Apabila kartu RFID tidak sesuai maka Di display LCD muncul "Kartu Salah" dan Relay tidak aktif serta Buzzer berbunyi 3 kali. 


\section{Card RFID (RFID Tag)} $\operatorname{Jarak}(\mathrm{mm})$

\section{Reader RFID}

Gambar 15. Jarak Kartu pada RFID Reader

Ujicoba kemampuan jarak dari suatu sensor dan ID Program dari kartu RFID maka dapat dilihat pada Tabel 1 berikut ini :

Tabel 1. Pengujian Sensor RFID

\begin{tabular}{|c|c|c|c|c|c|c|c|}
\hline $\mathrm{Uji}$ & \multicolumn{7}{|c|}{ Jarak: Sensor (MFRC522 dengan RFID Tag) pada RFID } \\
\hline Coba & $1 \mathrm{~mm}$ & $2 \mathrm{~mm}$ & $3 \mathrm{~mm}$ & $4 \mathrm{~mm}$ & $5 \mathrm{~mm}$ & $6 \mathrm{~mm}$ & $7 \mathrm{~mm}$ \\
\hline 1 & Terdetelksi & Terdetelksi & Terdatelssi & Terdetelssi & Terdetelksi & $\begin{array}{c}\text { Tidak } \\
\text { Terdetelssi }\end{array}$ & $\begin{array}{r:}\text { Tidak: } \\
\text { Terdeteks: }\end{array}$ \\
\hline 2 & Terdeteksi & Terdetelksi & Terdetelssi & Terdetelksi & Terdetelksi & $\begin{array}{c}\text { Tidak } \\
\text { Terdetelksi }\end{array}$ & $\begin{array}{r:}\text { Tidak } \\
\text { Terdetelas: }\end{array}$ \\
\hline 3 & Terdetelksi & Terdetelksi & Terdetelksi & Terdetelksi & $\begin{array}{c}\text { Tidak } \\
\text { Terdetelksi }\end{array}$ & $\begin{array}{c}\text { Tidak } \\
\text { Terdetelksi }\end{array}$ & $\begin{array}{c}\text { Tidak } \\
\text { Terdetelks: }\end{array}$ \\
\hline 4 & Terdetelksi & Terdetelksi & Terdetelzsi & Terdetelksi & Terdetelksi & $\begin{array}{c}\text { Tidak } \\
\text { Terdetelksi }\end{array}$ & $\begin{array}{r:}\text { Tidak } \\
\text { Terdetelks: }\end{array}$ \\
\hline 5 & Terdetelssi & Terdeteksi & Terdetelksi & Terdetelksi & Terdetelksi & $\begin{array}{c}\text { Tidak } \\
\text { Terdatelsai }\end{array}$ & $\begin{array}{c}\text { Tidak } \\
\text { Terdeteks }\end{array}$ \\
\hline
\end{tabular}

Pada Tabel 1 pengujian jarak sensor terdeteksi antara RFID Tag dengan RFID Reader hanya berjarak sampai $5 \mathrm{~mm}$, apabila melebihi batasan jarak tersebut, sensor tidak bereaksi dan Sistem pengaman sepeda Motor Honda Beat tidak berfungsi.

\section{Pengujian Kode Kartu RFID}

Tabel 2. Pengujian Kartu ID ( RFID Card )

\begin{tabular}{|l|c|c|c|c|c|}
\hline Kartu & Kode Kartu & Status & Tampilan LCD & Relay & Buzzer \\
\hline Kartu 1 & c7933133 & Berhasil & $\begin{array}{c}\text { Smartkey OK. } \\
\text { Silahkan Stater }\end{array}$ & Aktif (ON) & Beep 2 kaali \\
\hline Kartu 2 & daebfd10 & Salah & Kartu salah & $\begin{array}{c}\text { Tidak Aktif } \\
\text { (OFF) }\end{array}$ & Beep 3 kali \\
\hline Kartu 3 & 35 e7a875 & Salah & Kartu salah & $\begin{array}{c}\text { Tidak Aktif } \\
\text { (OFF) }\end{array}$ & Beep 3 kaali \\
\hline Kartu 3 & 62 c0634a & Salah & Kartu salah & $\begin{array}{c}\text { Tidak Aktif } \\
\text { (OFF) }\end{array}$ & Beep 3 kaali \\
\hline
\end{tabular}


Pada Tabel 2 ID Card dilakukan dengan beberap kartu yang berbeda, kartu pertama dengan ID sesuai maka sensor terdekteksi dan LCD akan menampilkan "Smartkey OK. Silahkan Stater", buzzer menyala 2 kali dan apabila kartu ID tidak sesuai LCD akan menampilkan "Kartu Salah" dan Buzzer akan menyala 3 kali

\section{Pengujian Kepekaan RFID Tag}

Tabel 3. Pengujian Kepekaan RFID Tag

\begin{tabular}{|c|c|c|}
\hline \multicolumn{3}{|c|}{ RFID Tag ( Kartu RFID ) c7933133 } \\
\hline No & Waktu & Status \\
\hline 1 & 1 detik & Tidak terbaca \\
\hline 2 & 2 detik & Terbaca \\
\hline 3 & 3 detik & Terbaca \\
\hline 4 & 4 detik & Terbaca \\
\hline 5 & 5 detik & Terbaca \\
\hline
\end{tabular}

Dari Tabel 3 Hasil uji coba RFID Tag pada kartu dihitung dari satuan detik, reader dapat membaca hanya 2 sampai 3 detik saja. Reader hanya membaca tag dari hasil terakhir card ditempelkan.

\section{Penempatan Komponen di Sepeda Motor Honda Beat.}

Untuk suatu rancangan system dibuat ditunjukan pada Gambar 16. Dan untuk penempatan tiap-tiap komponen adalah:

1. Arduino Uno yang terhubungkan dengan IC7805 akan diletakan di belakang plat nomer depan atau belakang lampu utama depan Motor Honda Beat

2. Relay $5 \mathrm{~V}$ yang telah terhubung dengan konci kontak diletakan pada kerangka dalam dekat kunci kontak motor di bawah kemudi sepeda motor Honda Beat.

3. Untuk reader RFID Modul RC 522 yang telah disambung dengan kabel sebagai perangkat tambahan diletakan dan di stang setir kiri pada bagian dalam ataupun bagian dalam dari casing lampu pada kendaraan bermotor.

4. LCD RFID diletakkan di bagasi depan bagian kanan dibawah kemudi. Dibuat tempat tambahan agar bisa terlihat.

5. Tag yang berfungsi sebagai smart card diikutkan dengan gantungan kunci motor yang dari pabrik 


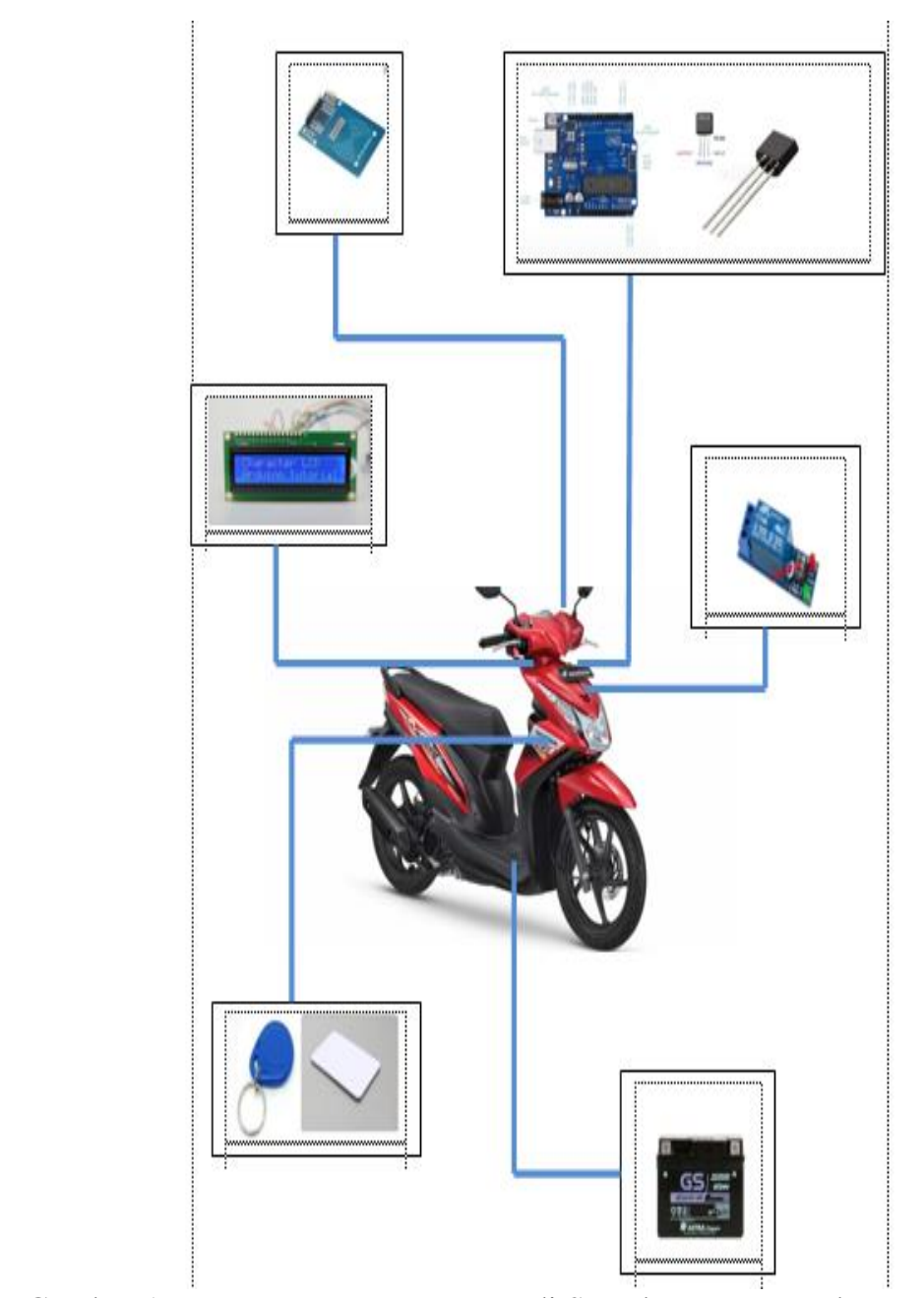

Gambar 16. Penempatan Komponen di Sepeda Motor Honda Beat

\section{KESIMPULAN}

Berdasarkan dari hasil penelitian yang dilakukan maka dapat disimpulkan bahwa: 1) RFID yang dipakai menggunakan frekuensi Band Low Frequency dengan batasan frekuensi 125 $\mathrm{KHz}-134 \mathrm{KHz}$ dengan penggunaanya jarak yang pendek, untuk membaca suatu informasi dari sebuah device skala kecil yang disebut tag atau transponder (transmitter danresponder). Tag RFID akan mengenali diri sendiri disaat mendeteksi suatu sinyal dari device yang kompatibel, yaitu pembacaan RFID (RFID reader). Dimana RFID reader dikoneksikan dengan mikrokontroller Arduino Uno. 2) Radio Frequency Identification (RFID) merupakan sebuah system yang mentransmisikan identitas berupa nomor atau kode unik dari suatu objek menggunakan gelombang radio. Teknologi ini termasuk bagian dari suatu teknologi identifikasi secara otomatis seperti barcode, optical character reader, dan teknologi biometric dan lain sebagainya. 3) Sistem Pengaman RFID pada sepeda motor Honda Beat ini memrlukan komponen tambahan jika langsung menggunakan catu daya dari baterai berupa regulator digunakan untuk menurunkan tegangan 12 Volt menjadi 5 Volt. Disini penulis memakai IC 7805. Tp jika akan menggunakan catu daya selain dari baterai berarti memerlukan power bank sebesar tegangan 5 Volt. 


\section{REFERENSI}

[1] W. Isyanto, H., Solikhin, A., \& Ibrahim, "Perancangan dan Implementasi Security System pada Sepeda Motor Menggunakan RFID Sensor Berbasis Raspberry Pi," Resist. (elektRonika kEndali Telekomun. tenaga List. kOmputeR), vol. 2, no. 1, pp. 29-38, 2019.

[2] Supriyono, Heru, and A. D. N. Setyawan, "Perancangan Immobilizer Berbasis RFID untuk Sepeda Motor,” Emit. J. Tek. Elektro, vol. 16, no. 2, pp. 69-73, 2016.

[3] A. Kadir, Panduan Praktis Mempelajari Aplikasi Mikrokontroler dan Pemrogramannya Menggunakan Arduino. Yogyakarta: Andi Offset, 2012.

[4] I. Prasetya, Dwiyana, and M. Mushlihudin, "Sistem Keamanan Sepeda Motor Menggunakan Kata Sandi Berbasis Arduino Nano," J. Ilm. Tek. Elektro Komput. Dan Inform., vol. 4, no. 1, pp. 11-19, 2018.

[5] S. Suradi, "Perancangan Kunci Kontak Sepeda Motor Menggunakan Rfid Berbasis Arduino Uno," ILTEK J. Teknol., vol. 13, no. 2, pp. 1949-1952, 2018. 